Bull. Mater. Sci., Vol. 23, No. 4, August 2000, pp. 309-312. (C) Indian Academy of Sciences.

\title{
Gas-chromism in ultrasonic spray pyrolyzed tungsten oxide thin films
}

\author{
P S PATIL \\ Department of Physics, Shivaji University, Kolhapur 416 004, India
}

MS received 22 November 1999; revised 2 June 2000

\begin{abstract}
A simple and inexpensive ultrasonic spray pyrolysis (USP) technique has been employed to deposit tungsten oxide $\left(\mathrm{WO}_{3}\right)$ thin films by spraying $2 \cdot 0 \mathrm{mM}$ aqueous ammonium metatungstate solution onto the amorphous glass substrates kept at $250^{\circ} \mathrm{C}$. The films were further annealed at $400^{\circ} \mathrm{C}$ for $4 \mathrm{~h}$ in air. X-ray diffraction (XRD) technique was used to determine the crystallinity and to identify the $\mathrm{WO}_{3}$ phases. It was found that the films were sub-stoichiometric, $\mathrm{WO}_{3-z}$. To study gas-induced properties, a catalyzing layer of platinum (Pt) was sputtered onto it. The gas-induced electrical and optical properties of $\mathrm{Pt} / \mathrm{WO}_{3} /$ glass samples were studied and results reported. It was found that electrical resistivity decreased by a factor of 10 within 2 min and stabilized after $15 \mathrm{~min}$, after $\mathrm{H}_{2}$ gas exposure. Similarly the optical transmittance of the samples attenuated from $55 \%$ to $10 \%$ within 15-20 min. The reversible changes in electrical resistivity and optical transmittance were observed when the samples were exposed to oxygen. The response times and sensitivity of the samples were estimated.
\end{abstract}

Keywords. Ultrasonic spray pyrolysis; tungsten oxide; thin films; gas-chromism.

\section{Introduction}

Optically active thin film coatings can alter their optical properties as a function of changes in external conditions. The changeable optical characteristics can be obtained by different physical and chemical processes, in a large number of materials. These materials, recently named chromogenics (Lampert and Granqvist 1990), embrace both inorganic and organic materials. Optical coatings of these materials on architectural components are part of a programme aimed at reducing the cost of heating and cooling buildings. These materials flip between opaque and transparent states, when exposed to the gases and activated with a catalyzing layer they are known as 'gas-chromic'. They transmit sunlight nearly as well as a double-glazed window. They have no electrodes so they consist of only two layers and transmit more than $80 \%$ of all solar radiation. The suitability of the material to be used as gaschromic depends on its ability to return to its initial state upon removal of the cause that induced the change of its properties. Up to now, many materials have shown gaschromic effect. Among them are $\mathrm{SnO}_{2}$ for the flammable gases (Kamimori et al 1994), palladium for hydrogen (Hofheins et al 1995), (Ti, Sn) $\mathrm{O}_{2}$ for $\mathrm{CO}, \mathrm{C}_{3} \mathrm{H}_{8}, \mathrm{C}_{2} \mathrm{H}_{5} \mathrm{OH}$ and $\mathrm{H}_{2}$ gases (Arakawa et al 1999) and $\mathrm{WO}_{3}$ for nitrogen oxides (Akiyama et al 1993) and $\mathrm{H}_{2} \mathrm{~S}$ (Dwyer 1991).

Generally, the gas-chromic systems are described as having the configuration: Catalyzing metal/insertion compound (semiconductor)/insulator. $\mathrm{WO}_{3}$ is the most extensively studied insertion compound, which exhibits pronounced gas-chromism. The platinized bulk $\mathrm{WO}_{3}$ reacts with $\mathrm{H}_{2}$ at room temperature to form blue colour. This was first recognized by Khoobar in 1964. After this, several other catalyzing materials viz. Pd (Hobbs and Tseung 1972), optically semitransparent Pt (Degani et al 1987), Rh (Porter et al 1985) and Au (Davazoglou and Georgouleas 1998) were studied in the gas-chromic devices based on $\mathrm{WO}_{3}$. The $\mathrm{WO}_{3}$ films have been deposited mainly by using chemical vapour deposition and vacuum evaporation techniques.

The goal of this investigation was to examine the gaschromic effect in USP- $\mathrm{WO}_{3}$ thin films with $\mathrm{Pt}$ as a catalyzing material. The change in electrical resistivity and optical transmittance properties of $\mathrm{Pt} / \mathrm{WO}_{3}$ tandem samples, in presence of hydrogen and oxygen gases were studied. The preliminary results are reported.

\section{Experimental}

Ultrasonic spray pyrolysis involves the application of a fine mist of very small droplets containing the reactants onto the hot substrates. The critical operations of the spray pyrolysis technique are the preparation of uniform and fine droplets and the controlled thermal decomposition of these droplets.

Figure 1 shows a schematic diagram of the USP system used in the present study. It consists of a quartz reactor, a r.f. heater, ultrasonic nozzle and an exhaust system. To prepare $\mathrm{WO}_{3}$ thin films, the precursor solution was prepared by dissolving an appropriate quantity of hydrated ammonium metatungstate $\left(\mathrm{H}_{26} \mathrm{~N}_{6} \mathrm{O}_{41} \mathrm{~W}_{12}\right)$ in doubly distilled water. The concentration of the solution was $2 \mathrm{mM}$. This solution was sprayed through the ultrasonic nozzle, 
which was operated at $1 \mathrm{MHz}$, onto the preheated glass substrates. The substrate temperature was kept constant at $250^{\circ} \mathrm{C}$ and continuously monitored by a chromel-alumel thermocouple fixed to the metallic substrate holder. After many trials, the preparative parameters of the system were optimized to obtain uniform, pin hole free and adherent films of $\mathrm{WO}_{3}$. These values are represented in table 1 . After the deposition, the films were annealed at $400^{\circ} \mathrm{C}$ in air for $4 \mathrm{~h}$.

The film thickness was measured using a Dektak 3030 profilometer. The structure of the films was examined by conventional XRD technique. The XRD measurements were performed in a $\theta-2 \theta$ coupled geometry with a Siemens D-500 diffractometer using a copper anode.

After $\mathrm{WO}_{3}$ films were annealed, a $10 \mathrm{~nm}$ thick layer of Pt was sputtered on to it. To obtain ohmic contacts for the electrical measurements, Au contacts were sputtered on $\mathrm{Pt}$ layer. The sample geometry is shown in figure 2. The samples were then placed in a glass chamber consisting of inlet and outlet for gases. At the beginning of the experiment, the chamber was filled with nitrogen. The samples were then exposed to a gas flow of 5 vol. $\% \mathrm{H}_{2}$ in 95 vol. $\% \mathrm{~N}_{2}$ with $39 \mathrm{ml} / \mathrm{min}$ flow rate for about $30 \mathrm{~min}$. After this, gas flow was terminated and 10 vol. $\% \mathrm{O}_{2}$ in 90 vol.\% $\mathrm{N}_{2}$ gas was allowed to flow inside the chamber with the same rate and time. The relative humidity and operating temperature were $10 \%$ and $23^{\circ} \mathrm{C}$, respectively. The electrical resistivity was measured during $\mathrm{H}_{2}$ and $\mathrm{O}_{2}$ gas flows. The optical transmittance of the samples during the exposure of the gases was measured with the $\mathrm{He}-\mathrm{Ne}$ laser $(\lambda=633 \mathrm{~nm})$.

\section{Results and discussion}

During spray pyrolysis, the solution was atomized onto the preheated glass substrates. The droplets underwent

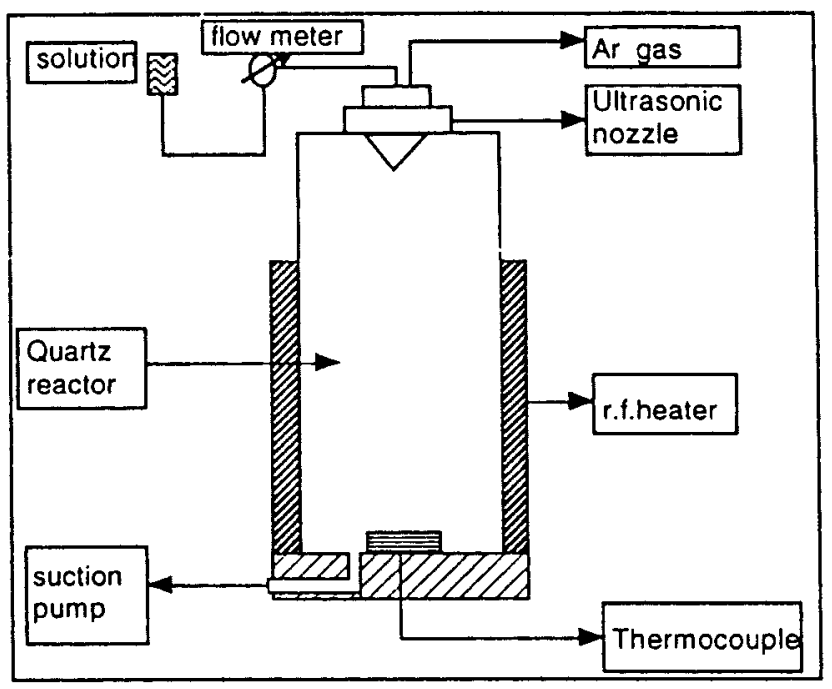

Figure 1. Schematic of USP technique for the deposition of $\mathrm{WO}_{3}$ films. evaporation, solute condensation and thermal decomposition which resulted in the film formation. In case of tungsten oxide thin films, following reaction took place:

$$
\begin{aligned}
2 \mathrm{~W}_{12} \mathrm{O}_{41} \mathrm{~N}_{6} \mathrm{H}_{26} \stackrel{250^{\circ} \mathrm{C}, \text { air }}{\longrightarrow} & 24 \mathrm{WO}_{3}+12 \mathrm{NH}_{3} \uparrow \\
+ & 8 \mathrm{H}_{2} \mathrm{O} \uparrow+\mathrm{O}_{2} \uparrow .
\end{aligned}
$$

The films were found to be uniform, pin hole free and well adherent to the amorphous glass substrates. The colour of the film was slightly whitish and changed to transparent yellow upon annealing at $400^{\circ} \mathrm{C}$ in air. Thickness of the film was $0.6 \mu \mathrm{m}$.

\subsection{Structural determination of $\mathrm{WO}_{3}$ thin films}

Figure 3 shows XRD pattern of $\mathrm{USP}-\mathrm{WO}_{3}$ thin film annealed at $400^{\circ} \mathrm{C}$ in air for $4 \mathrm{~h}$. It is observed that the films are polycrystalline and consist of well defined, high intense diffraction peaks corresponding to (020), (002), (220) and (400) planes. The ' $d$ ' values are compared with standard ' $d$ ' values from JCPDS data (35-270). The good agreement of ' $d$ ' values with this data indicates that the film structure is orthorhombic hydrated $\left(0.33 \mathrm{H}_{2} \mathrm{O}\right) \mathrm{WO}_{3}$. Additionally, few peaks corresponding to (200), (-403), (504) (750) and (014) planes are observed, which are assigned to oxygen deficient tungsten oxide (JCPDS card Nos: 36-392 and 41-745). Therefore it is concluded that

Table 1. Various optimized preparative parameters for USP$\mathrm{WO}_{3}$ thin films.

\begin{tabular}{ll}
\hline Parameter & Optimized value \\
\hline Nozzle to substrate distance & $14 \mathrm{~cm}$ \\
Nozzle power & $4 \cdot 5 \mathrm{~W}$ \\
Nozzle frequency & $1 \mathrm{MHz}$ \\
Solution concentration & $2 \mathrm{mM}$ \\
Solution spray rate & $1 \mathrm{ml} / \mathrm{min}$ \\
Quantity of solution sprayed & $10 \mathrm{ml}$ \\
Argon gas pressure & $1 \mathrm{bar}$ \\
Substrate temperature & $250 \pm 2^{\circ} \mathrm{C}$ \\
Inner diameter of the quartz reactor & $8 \cdot 3 \mathrm{~cm}$ \\
\hline
\end{tabular}

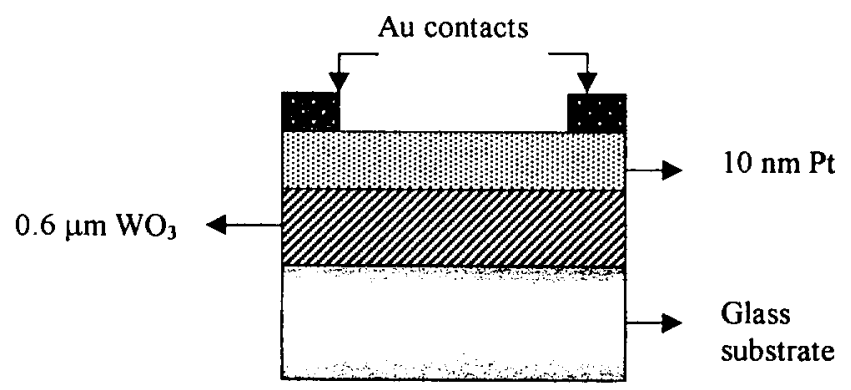

Figure 2. Various layers comprising gas-chromic sample. 
the resultant $\mathrm{USP}-\mathrm{WO}_{3}$ films are sub-stoichiometric, $\mathrm{WO}_{3-z}$. Analogous results are reported by others (Deneuville and Gerard 1978; Nanba and Yasui 1989).

\subsection{Electrical resistivity measurements}

Figure 4 shows the time evolution of the resistance of a $\mathrm{Pt} / \mathrm{WO}_{3}$ sample. It is observed that the resistance decreases significantly, by a factor of $10 \mathrm{in} 2 \mathrm{~min}$, in the presence of hydrogen. The response time (time interval necessary for the resistance to stabilize at its lowest value) is of the order of 14 to $16 \mathrm{~min}$, while the recovery time (time interval necessary to return to its initial value) is $\sim 24 \mathrm{~min}$. The values of response times (response and recovery times) are found to be larger than the reported values (Shaver 1967; Davazoglou and Georgouleas 1998) for $\mathrm{Pt} / \mathrm{WO}_{3}$ and $\mathrm{Au} / \mathrm{WO}_{3}$ systems respectively. However the sensitivity of USP-WO $\mathrm{W}_{3}$ samples is found to be higher than the reported value (Davazoglou and Georgouleas 1998). This may be due to different structures of $\mathrm{WO}_{3}$ films, which have resulted from various deposition techniques. Generally, the $\mathrm{WO}_{3}$ films deposited by chemical deposition technique consisted of metallic $\mathrm{W}$ and $\mathrm{WO}_{2}$ phases thereby exhibiting lower room temperature electrical resistivity (Davazoglou et al 1997). Whereas USP$\mathrm{WO}_{3}$ samples are hydrated and oxygen deficient phases, are more resistive than $\mathrm{W}$ or $\mathrm{WO}_{2}$ (Rogers et al 1969). Additionally, the variable amount of hydration content in the films is responsible for these discrepancies.

The resistance drop in the presence of hydrogen is associated with the colouration while increase in resistance after the introduction of oxygen is associated with bleach-

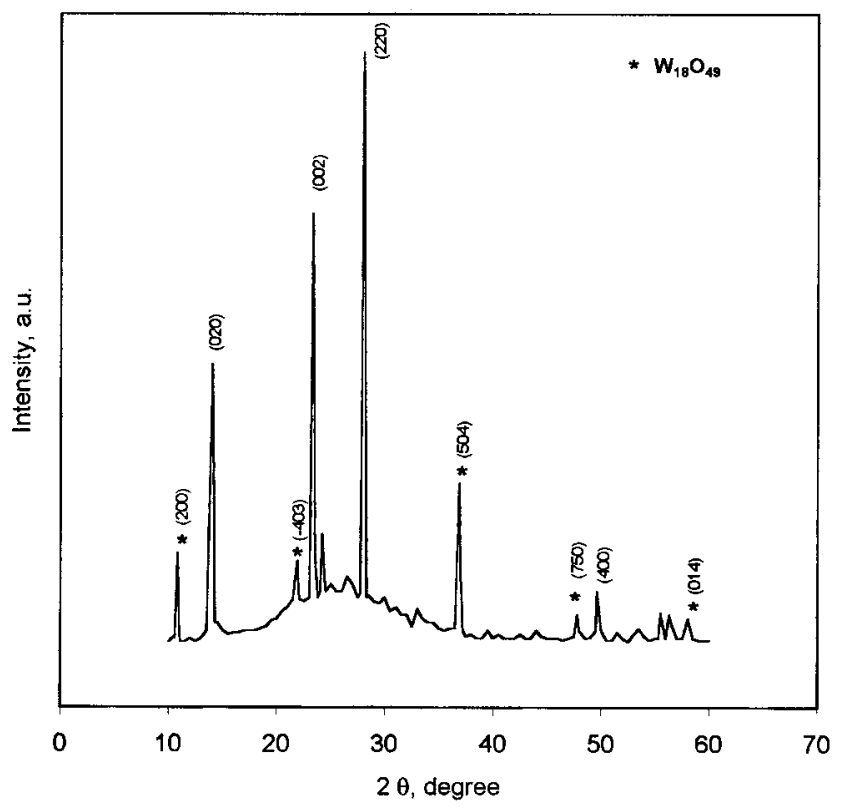

Figure 3. XRD pattern of USP- $\mathrm{WO}_{3}$ film annealed at $400^{\circ} \mathrm{C}$ for $4 \mathrm{~h}$. ing process. Thus it is shown that coating based on USP$\mathrm{WO}_{3}$ turn blue in the presence of hydrogen and become transparent when exposed to oxygen.

The colouration and bleaching mechanism can be explained on the basis of a model proposed by Rye and Ricco (1987).

By an exposure of $\mathrm{Pt} / \mathrm{WO}_{3}$ with hydrogen, the dissociation of $\mathrm{H}_{2}$ at the $\mathrm{Pt}$ surface is followed by a rapid diffusion of $\mathrm{H}$ to the $\mathrm{Pt} / \mathrm{WO}_{3}$ interface where a dipole layer is created. This results in a field across the interface, which in turn produces a sharp drop in the conduction band edge. This potential drop lowers the energy of the conduction band edge relative to the Fermi level of platinum and allows the charge transfer of electrons (hydrogen being electron donor) for the colouration of $\mathrm{WO}_{3}$.

When oxygen is in contact with the sample interface, similar description can be used, as described for the hydrogen above. Oxygen in the gas phase induces bleaching, because oxygen diffuses in the film, removes an electron from coloured $\mathrm{W}^{5+}$ states, and can occupy the oxygen vacancy. Thereby sample attains its initial state.

\subsection{Optical transmittance studies}

Figure 5 shows transmittance versus time of the $\mathrm{Pt} / \mathrm{WO}_{3}$ sample during the exposure of $\mathrm{H}_{2}$ and $\mathrm{O}_{2}$ containing gases. The gas compositions and flow rates are same as used for electrical resistivity experiment. The incidence of light proceeds from the side where $\mathrm{Pt}$ is placed, as shown in the insert in figure 5. It is observed that, after $\mathrm{H}_{2}$ gas is introduced transmittance $(T)$ decreases rapidly and the saturation value is reached after about $15 \mathrm{~min}$. While for $\mathrm{O}_{2}$ gas, $T$ increases relatively slowly and saturation is reached after $25 \mathrm{~min}$. The transmittance changes between $10 \%$ to

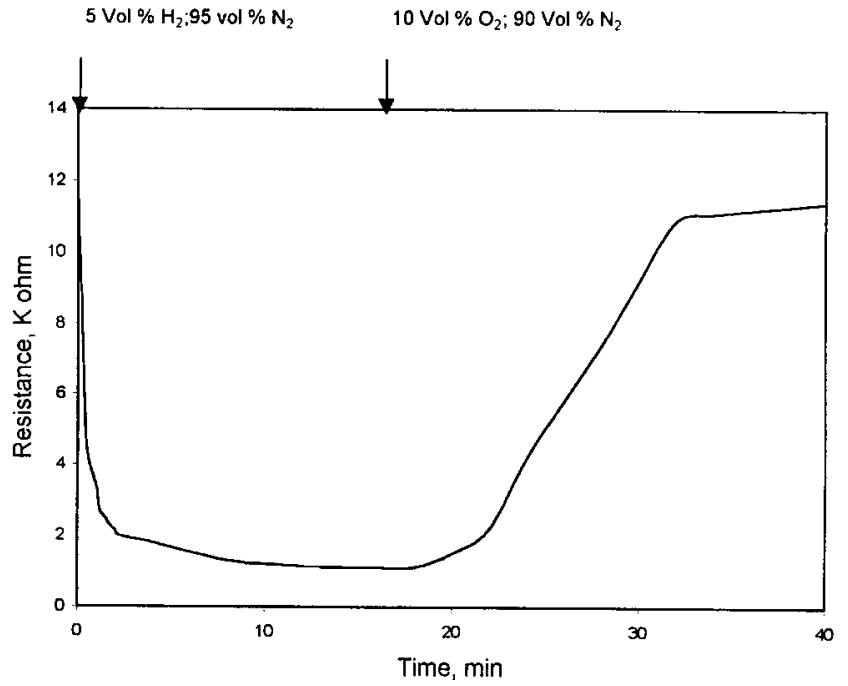

Figure 4. Variation of resistance with time for film $\mathrm{Pt} / \mathrm{WO}_{3}$ during exposure to 5 vol. $\% \mathrm{H}_{2}$ in 95 vol. $\% \mathrm{~N}_{2}$ and 10 vol. $\% \mathrm{O}_{2}$ in 90 vol. \% $\mathrm{N}_{2}$. 


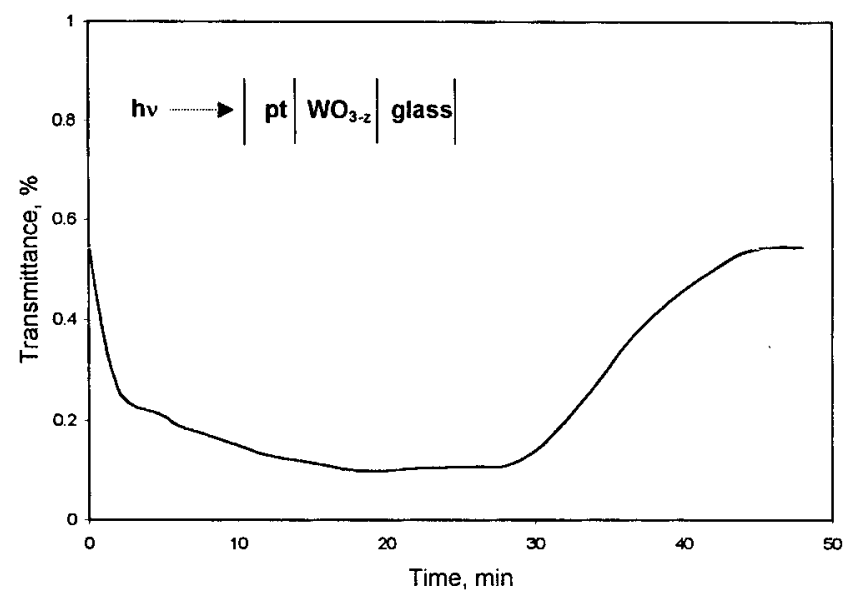

Figure 5. Variation of transmittance with time for $\mathrm{Pt} / \mathrm{WO}_{3}$ sample during exposure to $5 \mathrm{vol} \% \mathrm{H}_{2}$ in $95 \mathrm{vol} \% \mathrm{~N}_{2}$ and 10 vol. $\% \mathrm{O}_{2}$ in 90 vol. $\% \mathrm{~N}_{2}$.

55\%. Above results suggest that colouration process in $\mathrm{Pt} / \mathrm{WO}_{3}$ is faster than the bleaching process.

Further it is anticipated that the response times, transmittance and sensitivity of $\mathrm{Pt} / \mathrm{WO}_{3}$ samples depend on the density of the $\mathrm{WO}_{3}$ films, the $\mathrm{H}_{2}$ and $\mathrm{O}_{2}$ concentrations in the gases, thickness of the catalyzing materials and relative humidity. The investigations on the influence of these variants on gas-chromic effect of these samples are underway.

\section{Conclusions}

An USP technique has been employed to deposit good quality $\mathrm{WO}_{3}$ thin films. The films after annealing at $400^{\circ} \mathrm{C}$ for $4 \mathrm{~h}$ were substoichiometric, $\mathrm{WO}_{3-z}$. It has been shown that the resistivity and transmittance of USP- $\mathrm{WO}_{3}$ films with platinum as a catalyzing material presents reversible changes in presence of $\mathrm{H}_{2}$ and $\mathrm{O}_{2}$ containing gases. It is concluded that the samples exhibit relatively slower colouration and bleaching response but higher sensitivity to $\mathrm{H}_{2}$ and $\mathrm{O}_{2}$ containing gases.

\section{Acknowledgement}

Author wishes to thank Mr Stephan Kruger, Technical University, Berlin, Germany, for the experimental help.

\section{References}

Akiyama M, Zhang Z, Tamaki J, Miura N and Yamazoe N 1993 Sensors and Actuators B13-14 619

Arakawa S, Mogi K, Kikuta K, Yogo T and Hirano S 1999 J. Am. Ceram. Soc. 82225

Davazoglou D and Georgouleas K 1998 J. Electrochem. Soc. 1451346

Davazoglou D, Moutsakis A, Valamontes V, Psycharis V and Tsamakis D 1997 J. Electrochem. Soc. 144595

Degani Y, Sheng T T, Heller A, Aspnes D E, Stunda A A and Porter J D 1987 J. Electroanal. Chem. 228167

Deneuville A and Gerard P 1978 J. Electronic Mater. 7559

Dwyer D J 1991 Sensors and Actuators B5 155

Hobbs B S and Tseung A C C 1972 J. Electrochem. Soc. 119 580

Hofheins B, Lauf R and Felton J 1995 Sensors 12131

Kamimori M, Suzuki K, Ohya Y and Takahashi Y 1994 Jpn J. Appl. Phys. 336680

Khoober S J 1964 J. Phy. Chem. 68411

Lampert C M and Granqvist C G (eds) 1990 Large area chromogenics: materials and devices for transmittance control (Washington: SPIE Optical Engg. Press) 54

Nanba T and Yasui I 1989 J. Solid State Commun. 83304

Porter J D, Heller A and Aspnes D E 1985 Nature 313664

Rogers D B, Shannon R, Sleight A and Gillson J 1969 Inorg. Chem. 8841

Rye R R and Ricco A J 1987 J. Appl. Phys. 621084

Shaver P J 1967 Appl. Phys. Lett. 11255 